\title{
Development of a Conceptual Model for Diagnosis of Priority Directions of Science and Technologies
}

\author{
Andey Oleynik ${ }^{1}$, Andrey Gribkov ${ }^{1}$, Leonid. Chervyakov ${ }^{1}$ and Lubomir Dimitrov ${ }^{2}$ \\ ${ }^{1}$ Moscow State Technological University "STANKIN", RU-127055, Moscow, Russia \\ ${ }^{2}$ Technical University Sofia, BG-1000, Sofia, Bulgaria
}

\begin{abstract}
This article is dedicated to the development of a conceptual model for diagnosing priority areas of science and technology of the Russian Federation. The basic principles of the formation of the model and an enlarged list of controlled indicators allow to conduct a comprehensive assessment of the status and development of priority areas of science and technology. . The description of instrumental forecasting methods and a generalized algorithm for identifying the key factors/parameters, which impede the development of the object of analysis and cause critical bottlenecks, has been presented.
\end{abstract}

\section{Introduction}

One of the key factors determining the effectiveness of state policy in the field of science and technology development is the reliable diagnosis of the current state of this area, as well as the identification of key trends in its development.

The basis for this assessment is the formation of a diagnostic model. In order for this model to be workable, it must be based on a system of indicators (Prm) [1], which will allow a comprehensive assessment (Evt) of the development of priority areas of science and technology, that is:

$$
\lambda: \operatorname{Prm} \rightarrow \text { Evt }
$$

\section{Simulation model}

In this case, and this is important, the function $\lambda$ shows the relationship of indicators as a single assessment system. In addition, these indicators (or indicators) must be consistent (Ass) with the regulatory documents (Stn) of the head of state, Government, ministries, federal legislative and executive authorities, development institutions, etc. Formally, the Ass predicate must always be true, those:

$$
\operatorname{Ass}(\operatorname{Prm}, S t n)=\text { True }
$$

The number of monitored indicators must necessarily include the basic indicators for the implementation of the Strategy for Scientific and Technological Development of the Russian Federation, established by order of the Government of the Russian Federation of 08.15.2019 No. 1824-p. The composition of these criteria includes the following categories and indicators:
1. Separate (target) indicators reflecting (including in comparison with the values of the corresponding indicators of economically developed countries) the level of achievement of the implementation results and the goals of the Strategy for scientific and technological development of the Russian Federation (Category 1)

- Internal costs (Ic) for research and development from all sources at current prices as a percentage (Q1) of gross domestic product (Gp);

- Ratio (Q2) of extrabudgetary funds (Ef) and budget appropriations (Bf) as part of the internal costs of research and development.-

2. An indicator reflecting the impact of science and technology on the socio-economic development of the Russian Federation, including due to the transition to a model of big challenges (Category 2) The volume (Q3) of extra-budgetary funds raised as part of the implementation of comprehensive scientific and technical programs (projects), federal scientific and technical programs and projects of centers of the National Technological Initiative (Ef).

3. Indicators reflecting the state and effectiveness of the field of science, technology and innovation (Category 3)

- Place (Q4) of the Russian Federation by specific gravity (si) in the total number of articles (Na) in areas determined by the priorities of scientific and technological development, in publications indexed in international databases (Rk);

- Place (Q5) of the Russian Federation by specific gravity (vj) in the total number of applications for a patent for an invention $(\mathrm{Pv})$ filed in the world $(\mathrm{Tv})$ in areas determined by the priorities of scientific and technological development;

- The share (Q6) of innovative products (goods, services) created using the results of intellectual activity, 
the rights to which belong to Russian copyright holders (Ip), in gross domestic product (Gp);

- The share (Q7) of organizations (Io) implementing technological innovations in the total number of organizations (To);

- The ratio (Q8) of exports (Et) and imports (It) of technologies and services of a technological nature (including intellectual property rights);

- Export (Q9) of Russian high-tech products (Ep).

4. Indicators reflecting the quality of state regulation and service support of scientific, scientific, technical and innovative activities (Category 4):

- Share (Q10) of researchers under the age of 39 years $(\mathrm{Yr})$ in the total number of Russian researchers (Tr);

- Technical equipment (Q11) of the research and development sector (book value of machinery and equipment $(\mathrm{Ca})$ per researcher $(\mathrm{Tr})$.

These categories reflect the target model of the diagnostic process (Ef), which formally represents the four:

$$
E f=\langle L r, I s, P s, R q\rangle
$$

$$
\begin{array}{ll}
\text { Lr } & \text { - Results Level (Category 1), } \\
\text { Is } & \text { - Development Impact (Category 2) } \\
\text { Ps } & \text { - Status and Performance (Category 3), } \\
\text { Rq } & \text { - Quality regulation (Category 4). }
\end{array}
$$

Below is a mathematical model for calculating the considered indicators.

$$
\begin{aligned}
& E f=\langle L r, I s, P s, R q\rangle \\
& \Rightarrow \quad L r=\{Q 1, Q 2\} \\
& \Rightarrow \quad Q 2=\frac{E f}{B f} \\
& \Rightarrow \quad I s=\{Q 3\} \\
& \Rightarrow \quad Q 3=E f \\
& \Rightarrow P s=\{Q i \mid i=\overline{4,9}\} \\
& \Rightarrow \quad Q 6=\frac{I p}{G p} \\
& \Rightarrow \quad Q 7=\frac{I o}{T o} \\
& \Rightarrow \quad Q 8=\frac{E t}{I t} \\
& \Rightarrow \quad Q 9=E p \\
& \Rightarrow \quad R q=\{Q 10, Q 11\}
\end{aligned}
$$$$
\Rightarrow \quad Q 1=\frac{E f+B f}{G p} \cdot 100
$$$$
\Rightarrow \quad Q 4=i, \quad \exists i: s_{i-1} \prec s_{i} \prec s_{i+1}
$$$$
s_{i} \in S, \quad S=\left\{s_{k} \mid k=\overline{1, n}\right\}
$$$$
s_{i}=\frac{N a}{R k}
$$

$n$ - the number of countries participating in publications indexed in international databases$$
\Rightarrow Q 5=j, \quad \exists j: v_{j-1} \prec v_{j} \prec v_{j+1}
$$$$
v_{j} \in V, \quad V=\left\{v_{k} \mid k=\overline{1, m}\right\}
$$$$
v_{i}=\frac{P v}{T v}
$$

$m$ - number of countries applying for a patent for an invention

$$
\begin{array}{lll}
\Rightarrow & Q 10=\frac{Y r}{T r} \\
\Rightarrow & Q 11=\frac{C a}{T r}
\end{array}
$$

These indicators, being comparable with the values of the corresponding indicators of economically developed countries, reflect the level of achievement of the results of the implementation of the Strategy for scientific and technological development of the Russian Federation, including the impact of science and technology on the socio-economic development of the state in the face of great challenges, the state and effectiveness of the field of science, technology and innovation, the quality of state regulation and service support of scientific, scientific, technical and innovative activities.

All indicators used in the diagnostic process, as well as the goals themselves, must satisfy, as we see it, the SMART principle, which is widely known in project management, namely:

$S$ (Specific) - to be specific, understandable, reflect the real situation being defined in generally accepted terms;

M (Measurable) - be measurable directly or using available algorithms;

A (Achievable) - to be achievable, which is achieved by reasonable consideration of the prevailing conditions and the use of information from reliable sources;

$\mathrm{R}$ (Relevant) - be consistent with each other, which eliminates the imbalance and "one-sided" development of processes;

$\mathrm{T}$ (Time) - to be interconnected in time and reflect the real dynamics of change processes.

An important role here is played by the reliability of the information used for decision making. The following sources of information are noteworthy:

National and interstate statistical services (Federal State Statistic Service, Eurostat, etc.);

State authorities (federal ministries and governments of certain regions of the Russian Federation), state funds and research centers of Russia (within their area of competence), etc.;

Customs statistics from state customs services or international trade organizations (Federal Customs Service of Russia, WTO, International Trade Center, etc.);

Scientific centers, enterprises - manufacturers of products, industry associations, consumer unions;

Surveys, censuses, questionnaires (the reliability of such data is confirmed by additional materials).

The main resource (mechanism) for ensuring the system of indicators is new scientific knowledge. Therefore, along with a system of indicators, the determination of development goals in the form of an "image of the future" should become a prerequisite for ensuring the operability of the diagnostic model. In this case, this image should be a system ( $\mathrm{Scn}$ ) of priority scientific knowledge and technologies (Knd), built into the dynamic socio-economic system of Russia and the world (Com), i.e.: 


$$
\text { Scn }=(\text { Knd, R), Scn } \subset \text { Com }
$$

The set $\mathrm{R}$ reflects the interdisciplinarity of scientific knowledge and technology as a system.

The initial stage in the formation of this "image of the future" is the compilation of forecasts of scientific and technological development [2]. Forecasting tools $(v)$ include a fairly wide variety of methods. The most universal and affordable to use are [3]:

Perspective extrapolation - an approximation of the identified trends (Trd) of the previous period for a certain period of time $(\tau)$ to the future, i.e.

$$
\begin{gathered}
\operatorname{Trd}=\omega\left(\tau^{(\mathrm{k})}\right), \quad \exists \tau^{(\mathrm{k})}: \forall \tau^{(\mathrm{i})}, \\
\mathrm{i}=\{1, \mathrm{n}\} \rightarrow \tau^{(\mathrm{k})}>\tau^{(\mathrm{i})}
\end{gathered}
$$

The duration of the preceding period used to identify trends depends on the lead time and the specifics of the forecast. Extrapolation can be one-factor (the predicted indicator depends on only one factorial attribute, usually it is time) or multi-factor (the predicted indicator depends on several factor factors, for example, values of macroeconomic indicators):

Scripting (Scn). A scenario is a description (picture) of the future, drawn up taking into account plausible assumptions (Prp), i.e. $\mathrm{Scn}=\{\operatorname{Prp}, \mathrm{R}\}$, where $\mathrm{R}$ is the precedence relation (as a rule). Assumptions are formulated on the basis of observed development trends, voiced programs for the development of industries, enterprises, research areas, etc., assessing the needs of the market for new goods and services, and analyzing the macroeconomic environment. As a rule, the development forecast fits into a certain number of likely development scenarios;

Generalization (Gen) of plans and development programs (Pp) of the subjects of the socio-economic system for the forecast period, i.e. Gen $=\cap_{1}^{\mathrm{n}} \mathrm{Pp}^{(\mathrm{i})}$. The method involves collecting information on the main subjects of the market, analyzing business plans and development programs for research centers, enterprises and the state, assessing the reliability and feasibility of development plans and programs.

The applied task of the functioning of the diagnostic system is to obtain the information necessary to support and stimulate scientific and technological development in priority areas [4]. Taking into account the limited ability of the state to influence development processes in a market economy, in practice, the priority task for state policy is to "identify bottlenecks" and implement measures to overcome them.

The purpose of identifying "bottlenecks" is to identify key factors that impede the development of the object of analysis (in this case, the priority areas of scientific and technological development). The solution to this problem is carried out in several stages:

Formation of a set of characteristics (Con), reliably reflecting (describing) the current state of the object of analysis at various points in time;

The choice of a set of parameters (Per) that affect (being the causes) on the current state of the analysis object:

$$
\text { v: Per } \rightarrow \text { Con }
$$

The highest reliability of the analysis is achieved when quantitative dependencies of the characteristics of the object of analysis on the parameters affecting them are determined.

Determining the importance of each of the parameters, i.e.

$$
\mu\left(\operatorname{Per}^{(i)}\right)=\frac{\partial}{\partial \operatorname{Per}^{(i)}} v\left(\operatorname{Per}^{(i)}\right)
$$

The analysis includes a quantitative assessment of the degree of influence of the values of these parameters on the state of the object of analysis;

A comparative analysis (q) of each of the parameters recognized as important $\left(\mathrm{Per}^{(\mathrm{i})}\right)$, with a basic $\left(\mathrm{Per}^{(0)}\right)$ level (basic scale). The determination of the basic level (scale) is carried out on the basis of the study of similar objects of analysis (for example, the development of priority technologies in other countries or the development of science and technology in a separate industry, etc.). As a result of comparison, an assessment is formed for each of the parameters, i.e.:

$$
\begin{aligned}
& \forall \operatorname{Per}^{(\mathrm{i})} \mathrm{i}=\{1, \mathrm{n}\}: \mathrm{q}\left(\mathrm{Per}^{(\mathrm{i})}, \operatorname{Per}^{(0)}\right) \rightarrow \\
& \rightarrow \operatorname{Per}^{(\mathrm{k})}=\arg \operatorname{ext} \mathrm{q}\left(\mathrm{Per}^{(\mathrm{i})}, \operatorname{Per}^{(0)}\right)
\end{aligned}
$$

The parameter can have a high value $\left(\mathrm{Per}^{(\mathrm{i})}>\right.$ $\mathrm{Per}^{(0)}$ ) compared to the base level ("high level”, which promotes development), be comparable $\left(\mathrm{Per}^{(\mathrm{i})} \cong \mathrm{Per}^{(0)}\right.$ ) with a basic level ("normal level", approximately corresponding to similar objects of analysis, not hindering development), be lower than $\left(\operatorname{Per}^{(i)}<\operatorname{Per}^{(0)}\right)$ of the basic level ("low level" unfavorable for development).

Based on a comparative analysis, a list (list) of factors hindering development is formed. Priority in this list is given to those factors that have the greatest impact on development, as well as factors whose change most affects development. The factors of the latter group are often the basis for stimulating development without significant material costs.

The solution to the problem of identifying "bottlenecks", implemented within the framework of the diagnostic system, does not imply the formation of methods and means to overcome them (this is a much more diverse and complex task), however, reliable determination of factors that impede development is an essential part of solving the problem of overcoming development obstacles.

Thus, the conceptual model for diagnosing priority areas of science and technology includes the definition of a system of indicators (indicators), the formation of an "image of the future," based on a comparison with which a qualitative and quantitative assessment of development is carried out, as well as the development of a methodology for identifying "bottlenecks" in national innovation and a socio-economic system [5] that impedes development. 


\section{Conclusion}

The practical implementation of the system of diagnosing the priority areas of science and technology will require solving a substantial set of additional tasks, which include the tasks of collecting and processing data, analyzing the collected data and forming on their basis a reliable assessment of the current state and development trends of science and technology, the methodology for preparing and disseminating information for consumers (state authorities, research centers, enterprises and organizations), as well as determining the place, role and building diagnostic system into the organizational and managerial system of the state.

Acknowledgements. We would like to thank the Ministry of Science and Higher Education of the Russian Federation supported in the frame of grant NO. 05.601.21.0019 of 2019 with unique identification number RFMEFI60119X0019. This work was carried out using equipment provided by the Center of Collective Use of MSUT "STANKIN".

\section{References}

1. P.V. Glushchenko. Management of Economic Systems: electronic scientific journal, 1-21 (2011) https://elibrary.ru/item.asp?id=18380004 (accessed 11/21/2019)

2. S.K. Leontiev, A.M. Gubinsky, Technological forecasting and planning: Russian and foreign experience, prospects for the domestic defense industry (M.: Publishing house of Moscow University, 2014)

3. Yu.V. Solovyova, Bulletin of the Peoples' Friendship University of Russia. Series: Economics 1, 78-85 (2016)

4. I.B. Dakhkilgov, I.V. Kodolov, I.A. Schukin, Transport Business of Russia 1, 105-107 (2014)

5. A.V. Oleinik, Scientific and Technical Information. Series 1: Organization and Methods of Information Work, 2, 2-4 (2009)

6. Science in American. History sketches [Nauka poamerikanski. Ocherki istorii] (Moscow, Novoe literaturnoe obozrenie, 2014) [in Russian]

7. V.V. Ivanov, G.G. Malineckij, Russia: 21st century. Strategy of break. Technologies. Education. Science [Rossija: XXI vek. Strategija proryva. Tehnologii. Obrazovanie] (Nauka. Izd. 2-e. Moscow, LENAND, 2017) [in Russian]

8. F. Gallouj, K.M. Weber, M. Stare, L. Rubalcaba Technological Forecasting and Social Change 94, 80-96 (2015)

9. S.N. Grigoriev, M.P. Kozochkin, F.S. Sabirov, and A.A. Kutin, Proc. CIRP, 1, 599-604 (2012)

10. S.N. Grigoriev, V.A. Sinopalnikov, M.V. Tereshin, and V.D. Gurin, Measur. Techn., 55(5), 555-558 (2012)
11. S.N. Grigoriev, G.M. Martinov, Proc. CIRP, 41, 858-863 (2016)

12. S.N. Grigoriev, G.M. Martinov, Proc. CIRP, 14, 517-522 (2014)

13. A.V. Oleynik, L.V. Kuznetsova, V.E. Petrov, 2018 Proc. Int. Conf. "Quality Management, Transport and Information Security, Information Technologies", IT and QM and IS, 704-708 (2018)

14. A.G. Ivakhnenko, V.V. Kuts, O.Y. Erenkov, E.O. Ivakhnenko, A.V. Oleinik, Russian Engineering Research 37(10), 901-905 (2017)

15. E. Semenishchev et al. Infrared Tech. and Appl. XLV. Int. Soc. for Optics and Photonics, 11002, P.110022 (2019).

16. V.V. Voronin, R. Sizyakin, I. Svirin, A. Zelensky, A. Nadykto, SPIE-Intl Soc Optical Eng in Counterterrorism, Crime Fighting, Forensics, and Surveillance Technologies II 10802; (2018) doi:10.1117/12.2326806

17. Evgeny A. Semenishchev, Viacheslav Voronin, Aleksandr Zelensky, Igor Shraifel SPIE-Intl Soc Opti. Eng in Inf. Tech. and Applications XLV, (2019)

18. Infrared Technology and Applications XLV, Volume 11002; doi:10.1117/12.2519537

19. S.N. Grigoriev, V.D. Gurin, M.A. Volosova, and N. Y. Cherkasova, Materialwiss. Werkstofftech., 44(9), 790-796 (2013) 